\title{
Cioran e Schopenhauer: Duas visões romenas
}

\author{
José Thomaz Brum \\ Pontifícia Universidade Católica do Rio de Janeiro - PUC-Rio
}

\section{RESUMO}

Este artigo pretende apresentar dois diferentes pontos de vista sobre os ecos schopenhauerianos nas obras de Emil Cioran (1911-1995).

Palavras-chave: Cioran. Schopenhauer. Marta Petreu. Ciprian Valcan

\section{ABSTRACT}

This article aims to present two different points of view on the Schopenhauerian echoes in Emil Cioran's works.

Key-words: Cioran. Schopenhauer. Marta Petreu. Ciprian Valcan

Gostaria de apresentar, e comentar, dois pontos de vista sobre a relação entre Cioran e Schopenhauer: o de Marta Petreu e o de Ciprian Valcan.

Marta Petreu publicou, em tradução francesa, um artigo intitulado Schopenhauer et Cioran. Philosophies parallèles. Nele a autora inicialmente menciona o fato de que "a cultura romena moderna se coloca desde o início sob o signo de Schopenhauer"1, e também a extraordinária façanha do príncipe Zizin Cantacuzène, que traduziu para o francês os Aforismos para a sabedoria na vida, Da quádrupla raiz do princípio de razão suficiente e sobretudo $O$ mundo como vontade e representação. "Soberbo presente oferecido à cultura francesa", nota Petreu. Quanto a Cioran, Petreu observa que, entre suas fichas de leitura conservadas nos arquivos da família, há aquelas redigidas entre os dezoito e dezenove anos que falam de leituras das acima citadas traduções de Cantacuzène.

Mas as célebres cartas de juventude (1930-1934) endereçadas por Cioran ao amigo Bucur Tincu são os maiores exemplos, segundo Petreu, de "expressões tingidas de schopenhauerianismo" ". Entre elas, uma marcante, a segunda, datada de 23 de setembro de 1932, "testemunha o contato estreito de Cioran com Schopenhauer" ". Cioran fala aqui de seu ensaio intitulado As revelações da dor,

\footnotetext{
${ }^{1}$ PETREU, Marta. Schopenhauer et Cioran. Philosophies parallèles. In Eugène Van Itterbeek (s. dir.), Cahiers Emil Cioran. Approches critiques, vol II, Sibiu/Leuven, Éditions de L’Université Lucian Blaga/Les Sept Dormants, 2000, p.107.

${ }^{2}$ PETREU, Marta. Op cit, p. 108.

${ }^{3}$ Idem, p. 109

${ }^{4}$ Idem, p. 110.
} 
publicado em 1933 na revista $A z i$ (Hoje), e republicado em francês na antologia de textos de juventude Solitude et destin": "Tentara demonstrar que o destino individual, enquanto realidade interior, irracional e imanente, só se revela a nós através da dor, que esta é a única via positiva de compreensão interior dos problemas pessoais" interior' ou 'a dor enquanto realidade positiva' são nitidamente schopenhauerianos" ". Não por acaso o jornal espanhol El País, em seu suplemento literário Babelia de 9 de abril de 2011, publicou essa carta em espanhol para homenagear o centenário de Cioran.

Mas é na leitura das obras de juventude de Cioran, sobretudo em Nos cumes do desespero (1934), que Petreu enxerga elos de Cioran com Schopenhauer. A vida, segundo o jovem Cioran, "não tem nenhum sentido", "se mantém sem razão", "em seu dinamismo cego". Petreu vê aí a vontade de viver schopenhaueriana: "Embora a vida seja para mim um suplício, não posso renunciar a ela. Para ser sincero, deveria dizer que não sei porque vivo, nem porque não cesso de viver. A chave reside, provavelmente, na irracionalidade da vida, que faz com que esta se conserve sem razão"8. Diz Marta Petreu: "neste livro, a presença mais importante, subjacente, secreta, permanece a de Schopenhauer, embora possamos detectar nele traços da leitura cioraniana de Nietzsche, Pascal, Dostoievski, Bergson, Spengler e outros"9.

Petreu menciona também uma importante entrevista mais tardia de Cioran (maio de 1986) ao grande historiador húngaro François Fejtö: "Dresden foi uma das mais belas cidades do mundo. Schopenhauer escreveu lá a sua obra Die Welt als Wille und Vorstellung. Quando morei nessa cidade, eu era fascinado por Schopenhauer" ${ }^{\prime 10}$. Cioran morou em Dresden em 1935, no final de seu estágio alemão em que estudara com Nicolai Hartmann e com Ludwig Klages.

Petreu fala também do segundo livro do jovem Cioran, O livro dos enganos (Cartea amagirilor, 1936). Diz que já o seu título é schopenhaueriano: “engano”, "leurre", seria a "ilusão" schopenhaueriana. Cioran, "do fundo de suas ilusões"

\footnotetext{
${ }^{5}$ CIORAN, Emil. Solitude et destin. Paris, Arcades-Gallimard, 2004, p. 205 a 221.

6 Apud PETREU, Marta. Op cit p.110.

${ }^{7}$ Idem.

${ }^{8}$ CIORAN, Emil. Sur les cimes du désespoir. Trad. André Vornic, Paris, L'Herne, 1990, p. 72-73.

${ }^{9}$ PETREU, Marta. Op cit, p.116.

${ }^{10}$ CIORAN, Emil. Entretiens. Paris, Arcades-Gallimard, 1995, p. 190-191.
} 
(diz Petreu), enuncia "a tristeza de ser". Schopenhauer, por sua vez, repete o tempo todo - seguindo Calderón - que "o maior crime do homem é ter nascido". Conclui então a autora: "O livro dos enganos se coloca na proximidade do filósofo alemão igualmente por seus temas, dos quais os dominantes são: a individuação, a música e a santidade"11. E diz ainda: "A solução de Schopenhauer - sacudir as cadeias da vontade de viver por meio da santidade - torna-se em Cartea amagirilor e depois em Lacrimi si sfinti (1937) um hino dedicado aos santos"12. Se, em O livro dos enganos, Cioran diz que "ficaria incomodado se o considerassem discípulo de Schopenhauer ou de Nietzsche", no mesmo livro pode-se ler: "será que poderia conter a minha alegria se me chamassem de discípulo dos santos?"13.

Outro tema schopenhaueriano presente em Cioran, segundo Petreu, refere-se à "metafísica schopenhaueriana da cosmogênese" "14. Na visão de Schopenhauer, a vontade "engendra" o mundo sob a forma do tempo; assim "estar no mundo equivale a estar no tempo". Não pertencer ao tempo, "não ter nascido" ("n'être pas né"), é a regressão salvadora para Cioran, diz Petreu - aludindo a uma de suas obras francesas mais conhecidas: De l'inconvénient d'être né (1973). Cioran confirmaria assim a ideia de Schopenhauer de que "o pecado original é o crime da existência ela própria”.

Ciprian Valcan, por sua vez, em um artigo mais recente, Les idées schopenhaueriennes dans l'oeuvre roumaine de Cioran $^{15}$, retorna sobre as posições de Marta Petreu e coloca questões importantes. Lembra que a autora dissera, em sua obra principal, Un trecut deocheat sau 'Schimbarea la fatã a României' (1999), que "a metafísica schopenhaueriana juntamente com a filosofia da história e da cultura de Spengler seriam as duas fontes essenciais para compreender o pensamento de Cioran desde o início e até o fim" "16. E começa a criticar a ideia de Marta Petreu de que, nos dois livros de juventude de Cioran (Nos cumes do desespero e $O$ livro dos enganos) o fundamento seria a metafísica schopenhaueriana.

\footnotetext{
${ }^{11}$ PETREU, Marta. Op cit, p. 117.

${ }^{12}$ Idem, p. 118 .

${ }^{13}$ CIORAN, Emil. Le livre des leurres, Paris, Arcades-Gallimard, 1992, p. 246.

${ }^{14}$ PETREU, Marta. Op cit, p. 118.

${ }^{15}$ VALCAN, Ciprian. Les idées schopenhaueriennes dans l'oeuvre roumaine de Cioran. In Eugène Van Itterbeek (s. dir.), Cahiers Emil Cioran. Approches critiques, vol. X, Sibiu/Leuven, Éditions de L'Université Lucian Blaga/Les Sept Dormants, 2009, p. 34 a 50.

${ }^{16}$ VALCAN, Ciprian. Op cit p. 34.
} 
O primeiro alvo de Valcan contra essa pretensa origem schopenhaueriana das obras do jovem Cioran é a ideia de pessimismo. Ele afirma que nos escritos cioranianos de juventude não há nenhuma adesão ao "pessimismo implacável” de Schopenhauer. O que há é uma "visão heroica", uma "intensificação do vivido"17, marca visível de um nietzschianismo exaltado. Para fundamentar essa posição menciona, entre outros, o trecho seguinte de Lacrimi si sfinti: "Quanto mais leio os pessimistas, mais amo a vida. Após a leitura de Schopenhauer lamento não estar

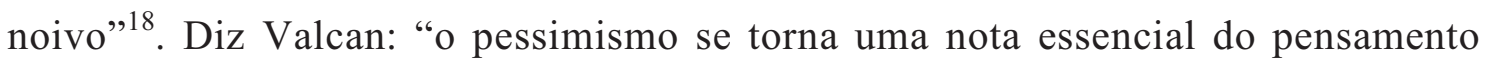
cioraniano apenas depois da renúncia ao nietzschianismo frenético de juventude, isto é, com a publicação de sua obra francesa" ${ }^{19}$. Aliás, Valcan sublinha que, nesse período francês, a grandeza trágica é substituída pelo "desapego", pela "contemplação irônica da criação e da dissolução das coisas"20 (resultado, diz ele, de suas leituras orientais ou budistas).

Outra posição cioraniana de juventude, apontada por Ciprian Valcan, revelase claramente crítica em relação a Schopenhauer (provavelmente o Schopenhauer de Metafísica do amor sexual): "Ele tem razão, Schopenhauer, em dizer que a vida é um sonho. Mas cai em uma grave inconsequência quando em vez de encorajar as ilusões, ele as desmascara, nos deixando entender que existiria algo fora delas. Tudo é engodo, amargo e doce" (Lacrimi si sfinti) $)^{21}$.

Ciprian Valcan vê o jovem Cioran como alguém que exalta o tempo todo a "exuberância" da vida, como um adversário obstinado de toda concepção que tenha por objetivo a "redução da vitalidade". Toda adesão à objetividade, à fria impessoalidade, nos afastaria do ritmo "palpitante" da vida: "L'objectivité est l'assassin de la vie et 'la vie' de l'esprit",22.

Mas é no que se refere ao fenômeno da individuação que o jovem Cioran segundo Ciprian Valcan - mais se afasta de Schopenhauer. As famosas páginas do Mundo que falam dos indivíduos como "fenômenos passageiros", que "nascem e passam", conduzem Schopenhauer à ideia de que a libertação do sofrimento só seria alcançada pela superação, pelo ultrapassamento do eu. A individualidade é

\footnotetext{
${ }^{17}$ Idem, p. 36.

${ }^{18}$ CIORAN, Emil. Des larmes et des saints, tradução Sanda Stolojan, Paris, L’Herne, 1987, p. 117. 
um mal - segundo Schopenhauer - porque nos prende no mundo dos fenômenos, no mundo do egoísmo, no mundo do tempo. Segundo Valcan, "nada poderia ser mais estranho ao jovem Cioran do que a ideia de que a individualidade é um mal que deve ser ultrapassado, que o eu é um erro ao qual devemos escapar"23. O fenômeno da individuação é visto, pelo jovem Cioran, como "uma expressão da grandeza do destino humano, como uma realidade que deve ser protegida e exaltada justamente por causa da fragilidade e da tragicidade que ela contém" 24 .

Para exemplificar essa visão cioraniana, o autor cita uma impressionante passagem de O crepúsculo dos pensamentos (Amurgul Gândurilor, 1940):

\begin{abstract}
A separação dos seres do caos inicial criou o fenômeno da individuação, um verdadeiro esforço da vida em direção à lucidez. As individualidades se originaram como um grito de apelo em direção à consciência, e os seres triunfaram em seu esforço para se desligar da confusão do todo. Enquanto o homem permaneceu como ser e nada mais, a individuação não havia superado os limites da vida, pois se apoiava no todo e era tudo. Mas o impulso para si mesmo, retirando-o do centro do universo, lhe deu a ilusão de um infinito possível nas fronteiras individuais. É assim que o homem começou a perder o seu limite, e que a individuação se tornou castigo: aí reside a sua dolorosa grandeza. Já que, sem o curso aventureiro da individuação, o homem não seria nada ${ }^{25}$.
\end{abstract}

Para o jovem Cioran, nos diz Ciprian Valcan, a individuação não é uma "prisão temporária”, ela é “a única possibilidade de sair da armadilha da nãodiferenciação, do murmúrio obscuro do ser... o único meio de se opor à tirania do Uno" 26 . Outro texto do jovem Cioran, este de Cartea amagirilor, assim fala da individuação: “A individuação deu um nome à vida. Nós todos temos um nome; o mundo que precede a individuação é a vida sem nome, a vida sem rosto. Só a individuação deu um rosto à vida. Eis porque a ruína da individuação na morte é uma desfiguração"27. Segundo Ciprian Valcan, a obra de Cioran expõe essa "tendência de exaltação do princípio de individuação" até o Précis de

\footnotetext{
${ }^{23}$ VALCAN, Ciprian. Op cit, p. 43.

${ }^{24}$ Idem, p. 44.

${ }^{25}$ CIORAN, Emil. El ocaso del pensamiento, tradução Joaquín Garrigós, Barcelona, Tusquets, 1995, p. 184-185

${ }^{26}$ VALCAN, Ciprian. Op cit, p. 44.

${ }^{27}$ Apud VALCAN, Ciprian. Op cit, p. 45.
} 
décomposition (1949) ${ }^{28}$. A partir daí há uma "inversão radical" e Cioran aproximase muito mais de Schopenhauer (mesmo se essa modificação é sustentada por autoproclamadas "razões orientais ou budistas").

E Ciprian Valcan conclui o seu texto com uma verdadeira joia do pensamento cioraniano em que este exalta o eu contra as tendências "piedosas" ou "religiosas" que buscam atacá-lo ou controlá-lo: "O eu é uma obra de arte que se nutre do sofrimento que a religião busca apaziguar. E o homem não tem outra nobreza senão a de ser o seu próprio esteta. Ele construirá na dor a beleza de sua pequenez e formará a sua substância ao se consumir" (Bréviaire des vaincus) ${ }^{29}$.

A principal razão da oposição de Ciprian Valcan a um suposto schopenhauerismo do jovem Cioran é a ideia de que este seria "um adepto do pathos, das transformações radicais... um adorador do vivido, ao qual a ideia da renúncia, do afastamento dos sentidos, da expulsão da subjetividade não pode de forma alguma parecer mobilizadora" ${ }^{30}$. De acordo com essa visão, o jovem Cioran parece estar mais próximo do entusiasmo nietzschiano do que das consolações schopenhauerianas.

\footnotetext{
${ }^{28}$ Idem p. 46.

${ }^{29}$ Apud VALCAN, Ciprian. Op cit, p. 48-49.

${ }^{30}$ Idem, p.49.
} 